\title{
EDITORIAL
}

\section{In This Issue: Real Change Is Real Hard in the Real World}

\author{
Kurt C. Stange, $M D, P b D$, Editor \\ William R. Pbillips, MD, MPH, Senior Associate Editor
}

Ann Fam Med 2007:98-100. DOI: 10.1370/afm.684.

$\mathrm{T}$ his issue of Annals is devoted to original research, methodology, theory, and essay that show how difficult it is to improve practice in the real world. Rather than seeing the complexity of making positive change as a source of discouragement, we see the depth of these challenges as a beacon of hope. The hope stems from a sense that primary care research is increasingly grounded in the intricate and intimate community, practice, and health care system settings in which typical people live and receive their health care. ${ }^{1}$ This grounding provides needed resistance to the longing for quick, easy solutions to advancing knowledge and improving health care that are likely to be simplistic and incorrect. As American journalist $\mathrm{H}$. L. Mencken noted, "There is always an easy solution to every human problem — neat, plausible, and wrong."

Hunger to produce and sell dramatic research results is created and fed by the lay media and medical journals' need for news, researcher career pressures and egos, funders' eagerness to prove their value, and a public made hungry for the next big thing. ${ }^{3,4}$ These pressures are subtly enhanced by our widespread focus on the internal validity of studies at the expense of transportability of results to the real world of medical practice and patient care. Research in academic health centers, which often applies an evidence-based medicine paradigm to referral populations, can create cultures ${ }^{5,6}$ and selection biases within studies that doom the findings to limited transportability. ${ }^{7,8} \mathrm{We}$ experience a huge breach in the cycle of research into practice because the world of practice is not like the world of most studies. Then primary care clinicians are blamed if they pay more attention to the realities of patients and practice than the idealized breakthroughs of the artificial research setting.

The continual challenges of the changing practice environment are disheartening from the perspective of many quality improvement initiatives, which typically take a top-down approach. This perspective, ${ }^{9-13}$ which is increasingly dominant as health care administration becomes more centralized and heavily managed, seeks research that discovers a magic bullet which can then be disseminated with fidelity. The research in this issue (as well as the experience of those on the front lines of health care $)^{14}$ suggests that the reality of practice improvement is more complex and that this complexity resists easy change, ${ }^{15}$ which can be discouraging. But this complexity also is a source of heartening resilience and capacity for health care that is individualized on the basis of personal and community needs and values ${ }^{16}$ rather than being personalized on the basis of genetic testing designed to sell designer drugs. ${ }^{17-22}$ The complexity and local control of health care, to the extent that local control still exists, offer protection from centralized, simplified solutions that have the potential to reduce needed diversity ${ }^{15}$ and to cause great harm if the solutions are ineffective, unsustainable, or have adverse unintended consequences.

Let's look at what the articles in this issue have to say about the challenges of creating positive change, and about the importance of locale, resistance, resilience, concepts, methods, art, and hope.

\section{LOCALE}

The study by James and colleagues ${ }^{23}$ compares in-hospital mortality for patients with myocardial infarction in rural and urban hospitals. Like much of the prior literature, the authors find that mortality rates are higher in rural hospitals. By using a sophisticated riskadjustment procedure, however, they discover that the mortality difference can be accounted for by unmeasured confounding. These findings imply that, rather than providing poor-quality care, rural hospitals may be heroically providing similar-quality care for a more challenging patient population. Perhaps, rather than being the target for quality improvement interventions from the sages in the city, rural hospitals should be the 
focus of further in-depth study to see how they are accomplishing their work.

In contrast, the study by Gaynes et al finds little difference between depressed patients seen in the primary and specialty care settings. ${ }^{24}$ This finding shows that findings which are counter to current understanding from research in academic centers may emerge when the research is moved to the community setting. This study highlights the opportunity of finding common ground for similar needs in the primary and secondary care setting.

A cohort study of opioid-dependent patients evaluates the efficacy of buprenorphine-nalaxone treatment in the urban, community-based primary care setting. In this study, ${ }_{1}^{25}$ Himmelstein and colleagues find that more than one half of patients are sober at 6 months and that sobriety is more closely related to personal factors than to setting. These findings show that an intervention developed in the specialty setting can be translated into practice in the primary care community setting if the intervention meets the needs of patients and practices in those settings.

The clinical trial by Wadland and colleagues ${ }^{26}$ demonstrates the effect of an ambitious intervention designed to increase referrals from community-based primary care practices to a tobacco quit line. The low cost and modest but significant effect of this intervention shows the parallel between primary care and public health. Both have a less-selected population than the secondary and tertiary care settings. Both often are less expensive. Both have difficulty documenting dramatic effects of their services, but there is strong evidence that both provide tremendous value by having repeated small impacts on a large population over time. ${ }^{27,28}$ This report also shows the synergy of linking primary care and public health venues and approaches. ${ }^{29}$

An essay that offers lessons learned from caring for Hurricane Katrina refugees ${ }^{30}$ describes how an integrated health care system with a strong primary care component can meet a wide range of medical needs while keeping emergency services from being overwhelmed. Developing and maintaining capacity in the primary care infrastructure can help systems be prepared when the chips are down.

\section{RESISTANCE AND RESILIENCE}

The first of 2 studies by Krist and colleagues ${ }^{31}$ takes advantage of the natural experiment of a high-profile malpractice lawsuit for failure to screen for prostate cancer after an informed discussion. The highly publicized essay by the defendant in this suit detailed the dramatic personal effect of losing the suit, which put evidence-based medicine on trial. ${ }^{32}$ Many postulated a chilling effect on the practice of shared decision making with patients, ${ }^{33,34}$ a key component of the safe, effective, and personalized application of evidence-based medicine.$^{35}$ In a sign of the resilience of the doctor-patient interaction, the actual change is modest in this study of physicians close to the malpractice suit; most measures of shared decision making are unchanged.

The other study by Krist and colleagues ${ }^{36}$ is a clinical trial of an aid to promote patient involvement in the decision to screen for prostate cancer. This aid resulted in more engaged and informed patients, but shared decision control proved intractable. This result, as well as the limited change in the physicians in the authors' companion study ${ }^{31}$ of the effects of a malpractice lawsuit, shows both malleability and resistance to change. When such resistance is present, especially on the part of both patient and physician, it may be worth looking to see whether something worthwhile is going on that should be understood and preserved, rather than continuing to try to promote change to an idealized model. In this case, perhaps both patients and physicians want to share information, but sometimes the patient may want the physician to make an expert decision informed not only by knowledge of the scientific evidence but also by knowledge of the patient's wishes. This patient-informed decision making is different from patient decision making and from a paternalistic physician approach. ${ }^{37}$

\section{METHODS, ART, AND HOPE}

The methodology study by Fiscella and colleagues ${ }^{38}$ shows that standardized patients provide information on community practice which is complementary to information obtained from patient report. This study supports greater use of the standardized patient method to answer questions about the many unknown aspects of the clinician-patient relationship.

The essay by Werner ${ }^{39}$ explores the often unrecognized and unintended consequences of performance measurement. The article provides a cautionary note for the current headlong, ideologically-driven, and underinformed rush to incentivize the quality that can be measured, without fully considering the unintended consequences. The essay suggests that quality, particularly the unique value of primary care, may be compromised by efforts to improve the parts without adequate consideration of the effect on the whole. ${ }^{14,40}$

The issue closes with a joyful invitation to listen to jazz and read an essay that depicts how jazz is a melodious metaphor for the art of medicine. ${ }^{41}$ This art, which still eludes the measurement and attempts to control that characterize the dominant approach to science, is a source of motivation, joy, and high-quality care that 
bring together the improvising ensemble and the finelytuned health care team. This article, as well as accompanying jazz pieces that you can download from linked commercial sources, is featured in this issue's Annals Journal Club. ${ }^{42}$ Annals Journal Club also includes a wonderful essay by Howard Brody from the last issue of Annals. ${ }^{43}$ Together, these essays show how efforts to change practice should be preceded by efforts to understand practice, ${ }^{44}$ and how there is beauty as well as quality in much of what still eludes quantitative measurement.

We encourage readers to share experiences and ideas by joining the Annals online discussion at http:// www.AnnFamMed.org.

\section{References}

1. Miller WL, Phillips WR, Acheson LS, et al. New knowledge for and about primary care: A view through the looking glass of the Annals of Family Medicine. Ann Fam Med. 2005;3(3):197.

2. Mencken HL. "The Divine Afflatus," A Mencken Chrestomathy (1949) In: Columbia Encyclopedia, 6th ed. New York, NY: Columbia University Press; 2002:443.

3. Woolf SH, Johnson RE. The break-even point: when medical advances are less important than improving the fidelity with which they are delivered. Ann Fam Med. 2005;3(6):545-52.

4. Woolf $\mathrm{SH}$. Potential health and economic consequences of misplaced priorities. JAMA. 2007;297(5):523-526.

5. Green LA, Fryer GE, Yawn BP, Lanier D, Dovey SM. The ecology of medical care revisited. N Engl J Med. 2001;344(26):2021-2025.

6. Fryer GE Jr, Green LA, Dovey SM, Yawn BP, Phillips RL, Lanier D. Variation in the ecology of medical care. Ann Fam Med. 2003;1(2):81-89.

7. Green LW, Glasgow RE. Evaluating the relevance, generalization, and applicability of research: issues in external validation and translation methodology. Eval Health Professions. 2006;29(1):126-153.

8. Glasgow RE, Green LW, Klesges LM, et al. External validity: we need to do more. Ann Behav Med. 2006;31(2):105-108.

9. Tomson CR, Berwick DM. What can the UK learn from the USA about improving the quality and safety of healthcare? Clin Med. 2006;6(6):551-558.

10. Berwick D, Kabcenell A, Nolan T. No Toyota yet, but a start. A cadre of providers seeks to transform an inefficient industry--before it's too late. Mod Healthc. 2005;35(5):18-19.

11. Blumenthal D. The future of quality measurement and management in transforming health care system. JAMA. 1997;278(19):1622-1625.

12. Chassin MR. Improving the quality of health care: what strategy works? Bull N Y Acad Med. 1996;73:81-91.

13. Solberg LI, Hroscikoski MC, Sperl-Hillen JM, O'Connor PJ, Crabtree BF. Key issues in transforming health care organizations for quality: the case of advanced access. Jt Comm J Qual Saf. Jan 2004;30(1):15-24.

14. Casalino LP. The unintended consequences of measuring quality on the quality of medical care. N Engl J Med. 1999;341(15):1147-1150.

15. Miller WL, McDaniel RR, Crabtree BF, Stange KC. Practice jazz: Understanding variation in family practices using complexity science. J Fam Pract, 2001; 50(10):872-880.

16. Stange KC, Acheson LS. In this issue: communication in the era of 'personalized' medicine. Ann Fam Med. 2006; 4(3):194-196.

17. Snyderman R, Langheier J. Prospective health care: the second transformation of medicine. Genome Biol. 2006;7(2):104.

18. Lunshof JE, Pirmohamed M, Gurwitz D. Personalized medicine: decades away? Pharmacogenomics. 2006;7(2):237-241.

19. Ferrara J. Personalized medicine: challenges in assessing and capturing value in the commercial environment. Expert Rev Mol Diagn. 2006;6(2):129-131.
20. Kalow W. Pharmacogenetics and pharmacogenomics: origin, status, and the hope for personalized medicine. Pharmacogenomic.2006;6(3):162-165.

21. Ginsburg GS, McCarthy JJ. Personalized medicine: revolutionizing drug discovery and patient care. Trends Biotechnol. 2001;19(12):491-496.

22. Langreth $R$, Waldholz M. New era of personalized medicine: targeting drugs for each unique genetic profile. Oncologist. 1999;4(5):426-427.

23. James PA, Li P, Ward M. Myocardial infarction mortality in rural and urban hospitals: rethinking measures of quality of care. Ann Fam Med. 2007;5(2):105-111.

24. Gaynes BN, Rush A, Trivedi M, et al. Major depression symptoms in primary care and psychiatric care settings are minimally different: a cross-sectional analysis. Ann Fam Med. 2007;5(2):126-134.

25. Mintzer IL, Eisenberg M, Terra M, MacVane C, Woolhandler S, Himmelstein D. Treating opioid addiction with buprenorphine/naloxone in community-based, primary care settings. Ann Fam Med. 2007;5(2):146-150.

26. Wadland WC, Holtrop J, Weismantel D, Fadel H, Powell J, Pathak P. Practice-based referral rates to a tobacco cessation quitline: assessing the impact of comparative feedback vs general reminders. Ann Fam Med. 2007;5(2):135-142.

27. Donaldson M, Yordy K, Lohr K, Vanselow N. Primary Care. America's Health in a New Era. Washington, DC: National Academy Press; 1996.

28. Zaza, S, Briss PA, Harris KW, eds, for the Task Force on Community Preventive Services. The Guide to Community Preventive Services: What Works to Promote Health? New York, NY: Oxford University Press; 2005

29. Stange KC, Woolf SH, Gjeltema K. One minute for prevention: The power of leveraging to fulfill the promise of health behavior counseling. Am J Prev Med, 2002;22(4):320-323.

30. Edwards TD, Young R, Adonna L. Caring for a surge of Hurricane Katrina evacuees in primary care. Ann Fam Med. 2007;5(2):170-174.

31. Krist AH, Woolf $\mathrm{SH}$, Johnson R. How physicians approach prostate cancer screening before and after losing a lawsuit. Ann Fam Med. 2007;5(2):120-125.

32. Merenstein D. A piece of my mind. Winners and losers. JAMA. 2004;291(1):15-16.

33. Hogan RA. Evidence-based medicine on trial. JAMA. 2004;291 (14)1696-1697.

34. Bicket DP. Evidence-based medicine on trial. JAMA. 2004;291 (14)1696. [author reply 1698].

35. Woolf SH, Chan EC, Harris R, Sheridan SL, Braddock CH 3rd, Kaplan RM, Krist A, O'Connor AM, Tunis S. Promoting informed choice: transforming health care to dispense knowledge for decision making. Ann Intern Med. 2005;143(4):293-300.

36. Krist AH, Woolf $\mathrm{SH}$, Johnson R, Kerns J. Patient education on prostate cancer screening and involvement in decision making. Ann Fam Med. 2007;5(2):112-119.

37. Emanuel EJ, Emanuel LL. Four models of the physician-patient relationship. JAMA 1992;267(16):2221-2226.

38. Fiscella K, Franks P, Srinivasan M, Kravitz R, Epstein RM. Ratings of physician communication by real and standardized patients. Ann Fam Med. 2007;5(2):151-158.

39. Werner RM, Asch D. Clinical concerns about clinical performance measurement. Ann Fam Med. 2007;5(2):159-163.

40. Stange KC. The paradox of the parts and the whole in understanding and improving general practice. Int J Quality Health Care. 2002;14(4):267-268.

41. Haidet P. Jazz and the art of medicine: improvisation in the medical encounter. Ann Fam Med. 2007;5(2):164-169.

42. Stange KC. The art of family medicine. Ann Fam Med. 2007;5(2):iii.

43. Brody H. A headache at the end of the day. Ann Fam Med. 2007;5(1):81-83.

44. Stange KC. "One size doesn't fit all." Multimethod research yields new insights into interventions to improve preventive service delivery in family practice. J Fam Pract. 1996;43(4):358-360. 